\title{
Human Trafficking in South Asia: Issues of Corruption and Human Security
}

\author{
M. Bashir Uddin \\ Graduate School of International Cooperation Studies (GSICS), Kobe University, Japan \\ *Corresponding author: buddin54@gmail.com
}

\begin{abstract}
This paper addresses the situation of human trafficking in South Asia, particularly in India, Bangladesh and Nepal. It argues that the focus on trafficking either as an issue of illegal migration or prostitution still dominates the discourse of trafficking in these countries, which prioritizes state security over human security and does not adequately address the root causes of trafficking and the insecurity of trafficked individuals. The root causes or vulnerability factors of trafficking such as structural inequality, culturally sanctioned practices, poverty or economic insecurity, organ trade, bonded labor, gender violence, which are further exacerbated by corruption, have remained unrecognized in academic and policy areas. This paper argues that emphasis needs to be given to such underlying root causes, particularly to corruption that fuels human trafficking and threatens human security of the trafficked persons in South Asian countries. Accordingly, it provides policy recommendations to address and deal with the problem.
\end{abstract}

Keywords Human Trafficking, Human Security, Root Cause, Vulnerability Factor, Corruption, South Asia

\section{Introduction}

Human trafficking impedes socio-economic development, threatens national, regional and international security, and most importantly poses severe threats to the security of individuals. Human trafficking causes various socio-economic problems through, for instance, increasing organized criminal activities, contributing to a fragile socio-economic structure by spreading corruption and infectious disease like HIV/AIDS, and producing violence and greed in the society that harms both states and their citizens. This paper addresses the current situation of trafficking in South Asia, particularly in India, Bangladesh and Nepal. In South Asia, both cross-border and internal trafficking remain persistent problems. Available estimates reveal that South Asia is the home to the second largest number of internationally trafficked persons where around 150,000 people are trafficked annually (UNODC, 2007).

Historically the movement of people within the countries of the region has been prevalent. While on the move, people may become more vulnerable to exploitation in several forms. Trafficking for commercial sexual exploitation is considered as the most virulent form in South Asia. As countries in South Asia are experiencing rapid changes in economic, political, demographic and labor trends as an outcome of globalization, increasing demand for cheap labor and heavy population growth in the region encourages migration whether legal or illegal. The movement of young girls and women from Bangladesh and Nepal into Indian brothels is common. There is further movement of these women and girls to the Middle East as well as other destinations. At times of hardship, this starts out as illegal migration and ends up as trafficking. Such migration occurs in the backdrop of supply and demand in the sending and receiving countries. The supply side is associated with structural inequality, poverty, illiteracy and lack of opportunities for livelihood, whereas the demand rises from the need of cheap labor in the destination. Usually people from the poorer countries like Bangladesh and Nepal are at risk of exploitation and are trafficked to the neighboring country like India. An assessment study on sexually exploited children and youth by the Economic and Social Commission for Asia and Pacific (ESCAP) shows that in South Asia young girls from certain rural areas of Bangladesh, India and Nepal are trafficked for marriage and then sold into prostitution (Shamim, 2010).

In South Asia, debate on human trafficking has been mostly dominated by two approaches: prostitution/sex work approach and migration approach. The first approach forms an opposition among the activists and practitioners which focuses on whether prostitution should be banned or considered as a legitimate trade. The second approach focuses on the supply/demand nexus of trafficking, and stresses on promoting safe migration by separating trafficking from illegal migration. Anti-trafficking intervention by the governments, NGOs, INGOs and other donor agencies is basically centered on these two approaches in this region. It is important to consider that trafficking has been rarely referred to as an issue of individual security both in academic research and policy intervention. Research on trafficking as a security problem has yet to be taken into consideration. Addressing trafficking as an issue of migration and/or prostitution does 
not highlight the root causes or the insecurity of the trafficked persons. This paper sheds light on this problem by analyzing how trafficking entails a human security dimension in South Asian countries and how it is exacerbated by root causes, especially by corruption. Hence, the purpose of this paper is to explore the interrelationship among corruption, human trafficking and human security, which has been given little or no attention until recently. The interrelationship among these three constructs the conceptual framework of this research, which helps to look at the cases of human trafficking in South Asia.

This research is based on a qualitative method. Literature review and personal interviews were used to collect primary and secondary information to analyze the cases. The conceptual framework is built on the review of existing literature by using scholarly work on relevant concepts, while various research reports, dailies and interviews were used to explain the cases through the conceptual underpinning.

\section{The Concept of Human Trafficking}

Although there is a growing concern against human trafficking recently, it is not a new phenomenon. The origin of modern day human trafficking dates back to the late nineteenth century. The movement against the transatlantic slave trade during that period provided the framework to abolish 'white slave trade,' which symbolically represented the notion of 'female sexual slavery' as the result of trafficking in white women for prostitution. Followed by the movement, the first international legal instrument, the International Agreement for the Suppression of White Slave Traffic formed during 1904-1910, recognized trafficking in white women for prostitution in Europe. But changes in the racial notion and inadequate law enforcement later caused it to be replaced with another convention called Trafficking in Women and Children in 1921. Later the International Convention for the Suppression of the Traffic in Women of Full Age was adopted in 1933 by the League of Nations focusing on the distinction between adult women and female children.

Abovementioned early anti-trafficking conventions were eventually consolidated into the 1949 Convention known as the Suppression of the Traffic in Persons and of the Exploitation of the Prostitution of Others, which basically referred to trafficking as a problem associated with prostitution. Thus, having started in early decades, a series of international instruments against trafficking were adopted throughout the twentieth century. Finally, the beginning of the twenty first century witnessed the first major, widely and internationally accepted Convention against trafficking in Palermo, Italy. In 2000, as an outcome of previous international legal efforts, the UN Trafficking Protocol on Suppression of Trafficking in Women and Children was adopted. According to Article 3 of the Protocol, "Trafficking in persons shall mean the recruitment, transportation, transfer, harboring or receipt of persons, by means of the threat or use of force or other forms of coercion, of abduction, of fraud, of deception, of the abuse of power or of a position of vulnerability or of the giving or receiving of payments or benefits to achieve the consent of a person having control over another person, for the purpose of exploitation. Exploitation shall include, at a minimum, the exploitation of the prostitution of others or other form of sexual exploitation, forced labor or services, slavery or practices similar to slavery, servitude or the removal of organs" (UNODC, 2004).

From the beginning, the issue of human trafficking has always been a subject of huge debate both in theory and practice. This debate has grown centering on how the problem of trafficking relates to some other relevant issues such as prostitution, migration, organized crime and human rights. Trafficking is often equated with prostitution. This view considers that the only purpose of trafficking is for prostitution and that all trafficked persons are sexually exploited. Those who take this position consider that prostitution should be abolished in order to stop trafficking (radical feminist/abolitionist view). Opposing the view, another group (liberal feminist/sex worker group) acknowledges prostitution as sex work and hence they argue that migrant sex workers should not fall into the category of trafficked persons, or in other words they claim that all sex work is not necessarily the result of trafficking. This view has its root in the claim for legalization of prostitution (Samarasinghe, 2008). The migration approach to trafficking explains the supply and demand chains of trafficking in the backdrop of irregular movement of people across borders and focuses on restrictive migration policy to reduce the problem in source countries on the one hand, and considers trafficking as a problem of illegal migration that threatens the security of the host countries on the other. Part of this view sees trafficking as an illegal migration problem that often leads to the prosecution of the trafficked rather than the traffickers. These circumstances raise the issues of human rights abuse of the trafficked persons in the destination countries. The notion of state security does not help to understand this crucial point. Neither does it help to address the root causes or vulnerability factors of trafficking.

Apart from the debate over whether trafficking is a problem of prostitution or migration, less emphasis has been given to the questions such as: Why does trafficking happen in the first place? What are the underlying root causes of trafficking? How does trafficking cause human insecurity? If combating trafficking is the purpose, these are some questions that need to be taken into consideration.

\section{The Concept of Human Security}

The UNDP Human Development Report 1994 defines human security basically in two respects: "protection from sudden and harmful disruption in the patterns of daily life" and "safety from chronic threats such as hunger, disease and 
repression," which are represented by its twin goals: freedom from fear and freedom from want (UNDP, 1994). The Report explains that human security underlies seven important categories: economic, food, health, personal, environmental, community, and political security. These seven categories emphasize the notion of individuals' security, which is the focal point of the concept. The concept of human security arose after the cold war in response to the failure of traditional state security, which often causes the insecurity of the citizens. One of the assumptions of human security is that the incorporation of issues such as structural inequality, human rights, or environmental degradation, for example, to the area of security may lead to greater consideration to these issues, and therefore may expand the potential to be addressed meaningfully by the governments. Such assumption has led to an ongoing debate among the proponents of security in terms of its policy and academic efficiency. Some have argued that the concept is loosely defined and not very meaningful. For instance, Krause argues that the broad definition of human security is an itemized wish list and there is no clear gain from this (Krause cited in Tadjbakhsh and Chenoy, 2007). However, on the other hand, Thomas argues that human security focuses on the provision of basic material needs and realization of human dignity, including emancipation from oppressive power structures. It is not only about protecting people from violent threats but also empowering them to cope with situations such as to meet their basic needs: food, shelter, healthcare and education (Thomas, 2004). During the late 1990s, securitization theory emerged in response to narrowing down the broader concept of human security. The securitization theory pioneered by Barry Buzan, Ole Waever and their associates defines how an issue becomes securitized. Generally speaking securitization focuses on the interrelationship among three main elements: (i) an existential threat, (ii) securitizing actor/agent, and (iii) the referent object. A key criterion is how a certain threat is treated as legitimate by a particular audience, who then seeks to obtain the approval for emergency measures to be taken against the threat (Weaver, 1995). The objective of this framework is not what security is in reality, but what and how it is presented and successfully recognized as a threat. Although securitization theory has gained much attention in academia, it has been criticized for its state-centrism and lack of focus on the voices of individuals who are powerless and not in a position to speak about their own security.

Human trafficking is seen by the states mainly as a problem of state security, and thus they try to securitize their borders through border enforcement to prevent irregular migration including human trafficking. In this process of securitization, it could be argued that security of individuals is at stake when state security is prioritized. Kempadoo and Lobasz argue that destination states treat human trafficking primarily as a security threat to their borders and deportation of trafficked persons is often taken as anti-trafficking measures (Kempadoo, 2005; Lobasz, 2010). This way states as the securitizing actors securitize the referent object: trafficked migrants. This sometimes causes re-victimization of the trafficked. The impact of securitization is negative here. It is not a matter of concern for the states why these people are trafficked, in other words, what are the underlying reasons that push them across the borders. The notion of state security does not help to understand this crucial point. On the other hand, human security focuses on the underlying reasons such as poverty or economic insecurity, structural inequality, culturally sanctioned practices, gender violence, bonded labor system, organ trade, and corruption that make people more vulnerable to trafficking. Therefore, there is a pressing need to focus on these issues that create the initial platform of trafficking. The following section will look at what exactly root cause means, and particularly at how corruption as a root cause fuels the process of trafficking and causes human insecurity.

\section{Corruption as the Root Cause/Vulnerability Factor of Human Trafficking}

Although there is no particular definition of root causes, it could be argued that root causes underlie the mechanism that produces vulnerability of particular people in a particular situation. Generally speaking, root causes are the socio-economic, political and environmental factors that pose a threat to people's lives and exacerbate their vulnerability. At the same time, defining how vulnerability is constructed helps to understand the nature of root causes. Vulnerability is a term that has been used in environmental and social sciences in order to understand the ability of an individual or collectives to cope with an adverse situation which is intrinsically linked with root causes. Vulnerability is closely linked and sometimes is equated with insecurity. It implies uncertainty and dependence over economic, social, political and environmental factors over which people have no control. As Alexander (1995) points out "Vulnerability is equated with insecurity...People feel secure when they have control over their lives and environments...Accordingly they become insecure when they feel unable to control these things." Plate defines vulnerability into three categories: social, economic and environmental vulnerability. Social vulnerability is associated with social condition of individuals which include fragility of the personal condition and difference in entitlement (e.g., higher vulnerability of poor than rich, of women than men etc.). Economic vulnerability refers to poverty and economic losses and this type of vulnerability may cause through environmental vulnerability which is enhanced by adverse environmental conditions such as natural disasters (Plate, 2006). Nair and Sen describe vulnerability factors as those which relate to socio-economic and political factors that are interlinked and also can be divided into two categories: personal 
circumstances and socio-structural forces. Personal circumstances include a low level of literacy, lack of awareness, economic deprivation, a dysfunctional family system, physical/sexual abuse, polygamy etc. Socio-structural forces can be comprised of globalization, underdevelopment, conflicts, irregular migration with inadequate immigration policies, poor law enforcement, demand for cheap labor, urbanization, discriminatory practices and social exclusion (Nair and Sen, 2005).

Considering the above definitions it could be argued that vulnerability refers to the situation where people are socio-economically, politically and environmentally insecure and have no control over their lives in that given situation. The term vulnerability is sometimes used interchangeably with root causes. As one might argue that the abovementioned socio-economic, environmental or political aspects are in fact the root causes that lead to insecurity of people. Therefore, vulnerability would presumably represent a similar notion of root causes. They create an insecure environment where the former is a byproduct of the latter. In this way, vulnerability factors are closely interlinked with root causes. In this paper, the author uses the term 'vulnerability factors' as interlinked factors with 'root causes' or underlying reasons of trafficking.

Is corruption a root cause or vulnerability factor of trafficking? How corruption underlies the mechanism of trafficking? These are some fundamental questions that require further investigation if someone wants to know the impact of corruption on trafficking. Generally speaking, corruption exists almost everywhere in the world. It is a global problem. Agbu argues that corruption exists in varying degrees in different countries and whereas it may be rampant in some countries, it could also be moderate or low in others (Agbu, 2003). Shelly uses the term 'globalized corruption' that significantly contributes to the rise of human trafficking globally (Shelley, 2010). There is a positive link that could be found between corruption and various forms of crimes including trafficking. Referring to a report by Organization for Security and Co-operation in Europe (OSCE) Holmes argues that a strong correlation exists between corruption and trafficking as trafficking flourishes through the corruption of public officials. However, he also suggests that evidence is scarce and most of the argument regarding the correlation is based on assumption (Holmes, 2009).

Before looking at the correlation, it is important to look at the definition of corruption. Corruption is largely known as the act of abusing public power for private benefit. The World Bank explains corruption as "the abuse of public office for private gains. Public office is abused for private gain when an official accepts, solicits, or extorts a bribe. It is also abused when private agents actively offer bribes to circumvent public policies and processes for competitive advantage and profit. Public office can also be abused for personal benefit even if no bribery occurs, through patronage and nepotism, the theft of state assets or the diversion of state resources" (World Bank, 1997).

The working definition given by Transparency International, the prominent INGO working on corruption issues worldwide, defines corruption as "the abuse of entrusted power for private gain," which applies to both the public and private sectors (Transparency International, 2011). Every year Transparency International produces Corruption Perception Index (CPI), which ranks countries all over the world based on how corrupt their public sector is perceived to be reflecting the views of observers and experts from around the world. According to the INGO, "Studies show that victims tend to come from countries where the public sector is perceived to be highly corrupt, as measured by our Corruption Perception Index" (Transparency International, 2011). It also states that corruption exists at every stage of trafficking starting from transportation, recruitment to exploitation of trafficked victims. Transportation of victims can be facilitated through corruption within countries and across borders without detection or with fake paperwork. When the exploitation starts after arriving in destination, traffickers rely on corruption to avoid arrest. Bribes to police, courts and relevant public officers cause state institutions to turn a blind eye to traffickers or even to engage in the trafficking process (Transparency International, 2011).

Holmes provides some assumptions regarding how corruption can be directly and indirectly interrelate with trafficking. He argues that direct ways may involve: i) Running trafficking operation, ii) Participating in a trafficking operation through, for instance, warning criminal gangs about possible raids, turning a blind eye during border crossings, providing paperwork such as visas, or assisting traffickers to regain control over victims, iii) Participating in activities that involve trafficking such as prostitution, forced labor, etc. Indirect ways may involve: i) Using persons who are suspected of having been trafficked (e.g., in prostitution, in domestic help), ii) Refusing to investigate allegations of trafficking, iii) Supportive involvement in refusing to pass legislation to curb trafficking (Holmes, 2009).

From the above discussion it could be argued that corruption can perpetuate the process of trafficking when entrusted power is abused for personal gain. The following section will focus on trafficking-related corruption in South Asian countries.

\section{Human Trafficking, Corruption and Human Security in India, Bangladesh and Nepal}

It has been argued that India has the world's largest labor trafficking problem with hundreds of thousands of sex trafficking victims and millions of bonded laborers including forced child laborers (Ghosh, 2009). Based on the 
2007 estimates by the Ministry of Women and Child Development (MWCD), the number of individuals trafficked for commercial sexual exploitation in India is 2.8 million (Hameed et al., 2010). The Trafficking in Persons (TIP) Report of 2010 states that 90 percent of trafficking in India is internal which indicates that 10 percent is international/cross-border trafficking (US Department of State, 2010). Among the 10 percent of cross-border trafficking, approximately 2.17 percent occurs from Bangladesh and 2.6 percent from Nepal according to the study conducted by Sen and Nair (Sen and Nair, 2005). The study by Asian Development Bank (ADB)) reveals that around 10,000-15,000 and 5,000-11,000 people are trafficked per year respectively from Bangladesh and Nepal (ADB cited in Ali, 2005).

The most common root cause or vulnerability factor of trafficking in these three countries is economic insecurity or poverty. Poverty stricken states are the most vulnerable to trafficking. In India, although economic growth is rapidly increasing, the gap between rich and poor remains high. Women especially have lack of access to education and employment. Women and girl children face both gender inequality and caste discrimination in India and Nepal. Lower caste people have less access to education and jobs, and if they are women they have fewer options. The unique feature of the Devadasi and Deuki (culturally sanctioned prostitution) system that produces the supply of young women into commercial sexual exploitation is a distinct vulnerability factor of trafficking in India and Nepal. The number of bonded laborers is also high in India. It is also a part of the cultural practices in the rural areas where in order to repay parents' debt people are forced to debt bondage. Child labor also remains a severe problem in India and also in Bangladesh and Nepal. Millions of children work in hazardous situations in the glass bangle factories, brick kilns and circus industry where Indian, Bangladeshi and Nepali children are trafficked and exploited. In the case of Bangladesh, children are trafficked for camel jockeying. Natural disasters and organ trade are other important root causes of trafficking, especially in Bangladesh.

The Abovementioned root causes could be easier to find, analyze and conclude than the root cause like corruption. As mentioned earlier, the evidence of corruption-related trafficking is too scarce. Most of the research is based on a general assumption that corruption fuels trafficking, and thus eliminating corruption would be an effective way to fight against the problem. The reason for the scarcity of evidence is that public officials are usually not willing to speak about their involvement in corruption due to the fear of being suspended and imprisoned. On the other hand, although being aware of corrupt activities of public officials, trafficked victims often fear not to report them because of their own security. And when states are careless about the corrupt involvement of their own officials and treat trafficked persons as criminals, the victims become re-victimized; which Holmes identifies as the 'triple victimization' (Holmes, 2009). Due to such complexities, it is hard to find concrete evidence on this issue. However, there are some recent cases which may show the link between corruption and trafficking in these countries. Before exemplifying them, it is important to look at the situation of corruption in these countries. According to the CPI 2012, India, Bangladesh and Nepal have received the scores of 36, 26 and 27 out of 100 . The score 100 represents the countries which are clean and countries having the score 0 are most corrupted, particularly in the public sector (Transparency International, 2012). Hence, the CPI measurement indicates that the level of corruption exists in a greater extent in these countries. The purpose of this paper is actually not to address all types of corruptions that fit the definition by Transparency International or World Bank (i.e., all forms of public sector corruption), rather it is to acknowledge trafficking-related corruption in particular.

Although it would be hard to find proper data, some recent cases could be mentioned that would reveal the relationship between trafficking and corruption. In December 2011, the Asian Human Rights Commission (AHRC) reported a trafficking case of a 15 year old girl who was trafficked from West Bengal, a state of India, to Bangladesh. Although the family of the victim sought help from local police, they refused to provide any help. Even though the police registered the complaint, it is alleged that since then the police have done nothing to investigate the case or to rescue the girl from Bangladesh. It is suspected that the police remained inactive as they have accepted bribes from the cross-border child trafficking gang (AHRC, 2011).

In September 2011, the Daily Prothom Alo and the Daily Jaijai Din, two renowned national dailies of Bangladesh, revealed the news that from 2006 to 2011 around 200 people in 18 villages of the country have sold their kidneys because of extreme poverty. Their poor condition was deepened by the fact that they took loans with a high interest from some money lenders and NGOs. In order to repay their debts, they decided to sell their organs when convinced by the organ traders that they would receive a large amount of money. However, many of them did not get the amount as promised. The organ traders sold each kidney for US $\$ 4,000-5,000$, whereas they bought it from those poor people for US\$500-1,000. Selling and buying of organs is prohibited by the Article 9 and 10 of Organ Transplantation Act, 1999, but the practice of organ selling in Bangladesh seems to be on the rise according to the media. Media also revealed that sometimes renowned doctors in major public hospitals are involved in this organ trade ("200 needy people sell their kidneys," 2011; "Selling and buying of kidney," 2011). It is assumed that many of these kidneys are taken to India and other countries for transplantation. It is a new trend of trafficking of human organs that has become visible after the arrest of the offenders in September, 2011. This incident could be seen as the indirect way of abusing power by the doctors in organ trading who are affiliated with public hospitals. 
In order to find the correlation between corruption and trafficking, interviews with some trafficked persons from Bangladesh were conducted by the author. The author visited a health care center run by the Center for Women and Children Studies in Satkhira where a girl (name changed) shared her story of how she was trafficked and survived (Parvin, personal communication, September 8, 2011):

Parvin is 22 years old. She was married off at the age of 12 due to the poor economic condition of her family. She was often a victim of domestic violence by her husband. She has a boy child who is now 8 years old. When her child was 5 months old she was divorced by her husband. Helpless Parvin started a housemaid job and later began working in street construction in order to feed her child. During that time she got introduced to three men who allured her with a better job and took her to India. She was then sold to a brothel in Sambazar in West Bengal. She did not realize that she was sold. Every day 7-8 men came to her and she had to sell her body. Gradually she became sick. When she recovered she was again forced to do sex work. She was not paid for her work. Meanwhile her father tried to trace her and was informed that she was trafficked. $\mathrm{He}$ tried to inform the village chairman about the incident and asked for justice, but nothing happened. Then he filed a case against the traffickers but no one was arrested. Parvin came back to Bangladesh on June 19, 2011 by herself. She informed that the trafficker sold her for Tk. 4 lacks which is equivalent to US\$5,000.

While interviewing, Parvin became very emotional and mentioned that lawyers refused to deal with her case as she could not offer enough money to them. Although she requested them repeatedly to help her with the court proceedings, she did not get any help as she expected. This may show the indirect way, as Holmes argues, of how corruption interrelates trafficking. Economic insecurity and corruption can cause the re-victimization of trafficked victims.

The TIP Report of 2012 states that although human trafficking complicity (alleged) of some Bangladeshi government officials remains a major problem, the government has made no remarkable efforts to focus on this issue. The Report goes on to argue that, according to NGOs, there is a nexus among members of parliament, corrupt recruiting agencies, and brokers. According to NGOs, politicians and regional gangs were involved in human trafficking. In addition, NGOs and the media reported that some recruitment agencies in Dhaka have connections with some employers, which have subjected migrant workers to trafficking in destination countries. The Government of Bangladesh did not investigate or prosecute government officials suspected of trafficking-related complicity (TIP, 2012).

In the case of India, the Report mentions that corruption is rampant among law enforcement officials in India who reportedly continues to facilitate the movement of trafficked victims, protect alleged traffickers and brothel keepers, and receive bribes and sexual services from the brothels. The Indian government reported no prosecutions or convictions of government officials for trafficking-related offenses during the reporting period. In September 2011, the police arrested a member of the Border Security Force (BSF) for trafficking. He was released on bail as of December 2011, but there is no further information on that case. There was no information on the status of an arrest of a former member of parliament or an investigation on an Indian Administrative Services officer as noted in the 2011 TIP Report for his involvement in human trafficking (TIP, 2012). In another instance, it is interesting to note that many of the brothel owners surveyed by the organization called Action Research on Trafficking in Women And Children (ARTWAC) considered police raids either as an exercise for 'non-payment of regular money' to them, or as an effort to 'fill up their records' as well as to 'project their performance,' (Ghosh, 2009) Bribing law enforcement officers to avoid arrest or to seek advance information about any immediate raid are common tactics applied by brothel owners apart from the use of political connections to continue their trade uninterrupted. Sen and Nair in their study note that trafficking cannot be stopped as long as corrupt officials assist the criminals by their acts of omission and commission (Sen and Nair, 2005).

There are reports that even police officers are sometimes involved in trafficking. Another report by AHRC indicates that police officers from the Kerala State of India have been accused of running a human trafficking cartel in the state, which is linked with international criminal syndicates that supply women, children, and men (AHRC, 2013).

In July 2011, the author visited a shelter home of a prominent NGO named Sanlaap in Kolkata and interviewed some survivors who were trafficked from Bangladesh. One girl (name changed) among them told her story which is as follows (Arifa, personal communication, July 22, 2011):

21 year old Arifa was trafficked to Kolkata from Bangladesh in 2009. She was rescued with the help of Sanlaap. Since then she has been living in the shelter home of Sanlaap. Her repatriation order came in January 27, 2011 from Bangladesh. But her case in the court is still in the process and sometimes the absence of a judge has been making the procedure lengthy. Because of this reason her repatriation is still pending. She wants her speedy repatriation along with other Bangladeshi women who have been trafficked to India.

During the visit in Kolkata many NGOs have claimed that there are many cases of trafficked women that are pending in the courts. Usually, pending files do not move without bribes. This is a general assumption. It is also interesting to note that every one more or less knows about the problem but prefers not to discuss it. During the fieldwork in India, many said that corruption is the main problem that undermines anti-trafficking efforts. Police, judiciary and border guards are involved in trafficking 
themselves and make a regular profit (according to some NGOs in Kolkata). One INGO staff mentioned that corruption exists from top to bottom of the government structure which impedes justice delivery for the victims of trafficking (Anonymous INGO official, personal communication, July 14, 2011). NGOs also alleged that police do not effectively take action against brothels suspected of prostituting minors. The police action often worsens the situation of trafficked girls and women indebted to traffickers and brothel owners. Girls rescued from brothels are treated as criminals and in many cases when they are kept in government remand homes, they face sexual abuse by the police and staffs. In most cases brothel owners pay bribes to the authorities for returning the girls to the brothel. In such cases, the debt owned by the girls to the brothel owners and traffickers further increases as the costs of bribing is added to their labor debt.

In Nepal, trafficking-related complicity by government officials also exists. According to TIP Report 2012, traffickers use ties to politicians, business persons, state officials, police, customs officials, and border police to facilitate trafficking, including the paying of bribes for protection and favors. The Report mentions that some Nepali officials work with traffickers in providing fraudulent documents. The perpetrators who are politically connected can often escape prosecution and punishment. There were no investigations, prosecutions, or convictions of government officials for complicity in trafficking during the reporting period (TIP, 2012).

Aforementioned examples and cases may not cover the whole picture of trafficking-related corruption in South Asian countries, but provides some assumptions of how corruption affects the process of trafficking. Corruption, needless to say, creates the platform of trafficking. It violates human dignity and creates an insecure environment for vulnerable people who are on the move. In Particular, the human security of those who are trafficked due to corruption-related complicities is jeopardized. Corruption, human trafficking and human security are inextricably linked to each other. Corruption causes or perpetuates trafficking, and trafficking causes human insecurity. Focusing on state security does not help someone to understand this important correlation, which has not been addressed in these countries.

\section{Anti-Trafficking Intervention in India, Bangladesh and Nepal}

The governments, NGOs and INGOs have undertaken several measurers to deal with the problem of trafficking. Anti-trafficking intervention is usually divided into three phases: prevention, protection and prosecution. In the prevention phase, improvements have been observed as the governments have provided skills training for different officials through workshops, seminars, anti-trafficking materials (e.g., posters, publications, street dramas) and initiated awareness raising programs jointly with NGOs. Nonetheless, problems still remain in protection and prosecution. Prosecution of trafficking offence, especially registration of trafficking cases and conviction of traffickers, is considerably low in these countries. As for the protection phase, rescue and rehabilitation are some of the persisting challenges that the governments are experiencing. Simultaneously, repatriation of trafficked persons particularly from India to Bangladesh and Nepal is also a critical challenge for these countries. Governments of Bangladesh and Nepal have lack of resources and means to deal with the problem as they are already weighed down by other burning issues such as poverty, natural disaster and socio-political instability. On that account, the receiving country, India, should take the initiative, particularly in rescue and rehabilitation as well as repatriation for cross-border trafficking victims. They should respect the human rights of the trafficked persons and rectify their own obligations under the UN Trafficking Protocol and other anti-trafficking legal instruments.

International convention such as UN Trafficking Protocol has yet to be ratified by Bangladesh and Nepal. Besides, reforms of regional/national legislations have yet to be implemented in practice in all these countries because of the pitfalls associated with legal frameworks and conventions themselves. For example, at the regional level, although the South Asian Association for Regional Cooperation (SAARC) Trafficking Convention is being treated as a landmark for combined efforts to eradicate trafficking, the definition of trafficking provided in the Convention does not address trafficking from a general perspective. As Article 1 of the SAARC Trafficking Convention emphasizes prostitution as the main purpose of trafficking (SAARC Convention on Trafficking, 2002) and does not address the root causes or vulnerability factors, in particular corruption that increases the incidents of trafficking. Since trafficking does not occur only for prostitution, the text of the SAARC Convention needs to be revised in order to broaden its scope. At the international level, India ratified the UN Trafficking Protocol in 2011. However, it is important for Bangladesh and Nepal to ratify the Protocol in order to set international standards and measures on trafficking in persons in their domestic legislation and to develop a bilateral mechanism on easy and fast repatriation.

As for corruption-related trafficking, governments of these countries have made very little efforts to address the problem. For instance, Section 3 of the Immoral Traffic Prevention Act (ITPA) 1956 of India clearly prescribes punishment for keeping a brothel or allowing premises to be used as a brothel and such punishment becomes rigorous in the event of any second or subsequent conviction. Not only this but also police officers, as per law, may conduct search operations in such premises without a warrant. Yet, the political links and power of the brothel owners/managers sometimes work as disincentives for the police to take 
effective steps. They are therefore seldom brought to book and, on the contrary, the prostitutes are mostly arrested on charges of soliciting (Sing and Kapur, 2001). Even though government official are arrested after an allegation is made, they could easily be released on bail as mentioned earlier. The Indian Penal Code (IPC) 1860, The Prevention of Corruption Act (PCA) 1988, and the Prevention of Money Laundering Act 2002 are some of the existing laws that prohibit corruption in different forms. Section 407 and 409 of IPC declares punishment for breaching the trust by public servants and Section 7 of PCA punishes any act that involves receiving any forms of gratifications other than legal remuneration. These are general anti-corruption legal instruments in India. However, many have criticized their ineffectiveness.

In 2011, Indian Cabinet approved an anti-corruption bill that was an outcome of a mass movement against corruption in the country led by the social activist Anna Hazare. The aim of the bill was to set up an independent ombudsman who would have the power to prosecute politicians and civil servants (BBC, 2011). However, the bill was finally not passed by the upper house of the Cabinet and the movement was re-launched in 2012. In February 2013, the activist Anna went on for a hunger strike which generated a mass protest against corruption in the country (New York Times, 2013). If the anti-corruption bill is properly passed and implemented, it could be hoped that corruption-related trafficking would be reduced to some extent.

In the case of Bangladesh, the government prosecuted eight officials for complicity in trafficking during the period of June 2004 to June 2006 (TIP, 2006). As mentioned in the previous section, trafficking related complicities of government official in the country has remained a problem. The government of Bangladesh has enacted such measures as Anti-Corruption Commission Act, 2004; Money Laundering Act, 2002; Prevention of Corruption Act, 1947; and the Penal Code. Many of these instruments have provisions that prohibit and punish corruption in its all forms. Also, Bangladesh has established the Bureau of Anti-Corruption (BAC) which is in charge of handling corruption related cases. However, many of these laws remain ineffective.

In Nepal, several anti-corruption legal instruments are currently in place. Among them the Country Code of Nepal prohibits receiving any forms of bribery by the public officials. Other anti-corruption laws include Corruption Prevention Act, 2002; Commission for Investigation of Abuse of Authority Act, 1991; Good Governance (Management and Operation) Act, 2007; Anti-Money Laundering Act, 2008 and others. All of these acts prohibit corruption and corruption related activities and have different punishments and fines for the offenders.

In the international plane, although all these countries have ratified the United Nations Convention Against Corruption (UNCAC), the proper implementation of the articles of the Convention is yet a distant goal. There is a need for proper implementation of UNCAC as well as existing domestic laws in order to check trafficking -related corruption. According to the TIP Report, India, Bangladesh and Nepal have not made adequate efforts to combat trafficking. The TIP Report, published by the US Government every year, ranks countries all over the world based on their performance on combating trafficking focusing on prevention, protection and prosecution. The ranking is based on a four tiered system, which is evaluated by the Trafficking Victim Protection Act (TVPA), 2000. Countries belonging to tier-1 fully comply with minimum standards of TVPA to combat trafficking, while tier-2, tier-2 watch-list and tier-3 countries' governments do not fully comply with the minimum standards and are making less effort to fight against the crime.

Based on the TIP Report, India was placed to tier-2 watch-list from 2006 to 2010, and finally was removed from it by achieving the rank of tier-2 in 2011 which means India has taken some initiative to effectively deal with the problem. Bangladesh was in tier-2 from 2006 to 2008 but from 2009 its ranking went down to the tier-2 watch-list, which reveals the fact that the effort of the government to combat trafficking has been reduced over the last few years. However, the country's rank went up again to tier- 2 due to making some efforts in enacting a new anti-trafficking law called Human Trafficking Deterrence Act, 2011, which was passed in the parliament in 2012. This law defines trafficking more clearly and provides anti-trafficking measures comprehensively. The rank of Nepal has remained the same for the last seven years as a tier-2 country, which indicates that Nepal has been making more efforts than India and Bangladesh. However, although the TIP ranking is often criticized by NGOs, it still remains as the international yardstick for assessing the global anti-trafficking initiative. Considering the evaluation, India, Bangladesh and Nepal have not yet made enough efforts to combat trafficking (TIP Report, 2006-2012).

\section{Conclusion}

Human trafficking jeopardizes the dignity and security of trafficked individuals, and severely violates their human rights. Constitutions of India, Bangladesh and Nepal guarantee the equal rights of men and women, but they are often merely rhetoric when it comes to the question of practical implementation. In order to combat trafficking and thus to protect the human rights of the vulnerable people, strong political will of the governments in these countries is vital in implementing their anti-trafficking mandates. A particular focus on corruption-related complicities needs to be urgently addressed in order to ensure the security of the people who are vulnerable to trafficking. As mentioned earlier, if the purpose of the international community is to combat trafficking then the first and foremost question 
should be why trafficking happens at the first place or what are the root causes. Unless and until these questions are taken into serious consideration, reducing or eliminating trafficking would just remain as a never ending hope. A human security approach would help us to address the vulnerably factors or root causes of trafficking. It helps us to understand how root causes such as corruption reinforce the process of trafficking in these countries. Further, it could help us to consider how trafficked persons are victimized in the destination countries and how they are worthy of protection. At present such an approach is absent in the region. The governments of South Asia, particularly India, have always been concerned about national security. This becomes evident from the increasing amount of the defense budget in India. India raised its military budget from US\$32.7 billion in 2010-11 to US\$ 36.5 billion in 2011-12 (The Dawn, 2011). India ranked as the 9th largest military spender in the world in 2010 (Stockholm International Peace Research Institute, 2010). Such a huge military budget indicates that human security is not a priority concern for India. State security and any forms of threat associated with it are the major concerns for the country. There is a pressing need to reconsider the issues of human security such as trafficking in order eventually to strengthen the security of the states and their people in these countries. In order to make this happen future research should focus more on root causes, especially on corruption. Below are some basic recommendations to deal with corruption and trafficking: i) A human security based approach is currently absent in the region. Human security strengthens the notion of human rights. In order to uphold the security and dignity of the trafficked individual, countries should focus more on human security. ii) The anti-trafficking initiatives in these countries are not comprehensive enough to cover the root causes of human trafficking. They should vigorously focus on root causes, particularly on corruption and find proper ways to deal with them. iii) Trafficking is a gendered phenomenon. It is likely that people who are vulnerable are powerless, and many vulnerable women become victims of trafficking. In order to uphold a human security approach, emphasis must be given to gendered aspects of trafficking in future research. Gender empowerment would help to reduce both men and women's vulnerability to trafficking. iv) Education is a must to fight both corruption and trafficking. Secondary female education, for instance, which are 26.6, 30.8 and 17.9 respectively in these three countries, indicate a lower literacy rate of women than men (UNDP, 2011). Education can be a powerful weapon to fight against corruption. Long term secondary education is an important prerequisite in this regard. v) Trafficking is a demand-driven phenomenon that involves corruption. Reducing demand can help to reduce trafficking. More research is necessary on the demand side of trafficking. vi) There are enough anti-trafficking laws in these countries but they are seldom implemented. Implementation of these laws is essential to check the corruption related complicities. Accountability and efficiency of the law enforcers are very important. At the same time capacity building of law enforcement officials against corruption and trafficking is a must. vii) Immunity of the state officials needs to be redressed, which would help to curb corruption-related trafficking. viii) Media and civil society can play a crucial role to bring and expose corruption issues to the public. ix) Last but not the least, there is an urgent need for strong political will to fight against corruption. Nepotism is one of the basic criteria of politics in these countries, which works as an incentive for corruption. Politicians or the state leaders need to keep themselves beyond this favoritism. Not only that but also they need to be honest to properly use the entrusted power they have been given by the public.

\section{Author's Note}

Names of the interviewees have been changed or remained anonymous to protect confidentiality.

\section{REFERENCES}

200 needy people sell their kidneys. (September 3, 2011). The Daily Prothom Alo.

Agbu, O. (2003). Corruption and Human Trafficking: The Nigerian Case. West Africa Review, 4(1), 1-13.

Alexander, R. (1995). Putting the Earth First: Alternatives to Nuclear Security in Pacific Island States. Honolulu: Matsunaga Institute for Peace.

Ali, M. (2005). Treading along a Treacherous Trail: Research on Trafficking in Persons in South Asia. In F. Laczco and E. Gozdziak (Eds.), Data and Research on Human Trafficking: A Global Survey (pp. 141-164). Geneva: International Organization for Migration.

Asian Human Rights Commission, INDIA/BANGLADESH: Police refuse to take action to rescue a girl trafficked to Bangladesh. Retrieved on February 27, 2013 from http://www.humanrights.asia/news/urgent-appeals/AHRC-UAC-2 43-2011

Asian Human Rights Commission, INDIA: Police officers run human trafficking cartel. Retrieved on September 8, 2013 from http://www.humanrights.asia/news/ahrc-news/AHRC-STM-036-2 013

Ghosh, B. (2009). Trafficking in women and children in India: Nature, Dimensions and Strategies for Prevention. The International Journal of Human Rights, 13(5), 716-38.

Holmes, L. (2005). Human Trafficking and Corruption: Triple Victimization? In C. Freisendorf, (Ed.), Strategies Against Trafficking: The Role of Security Sector (pp. 83-114). Vienna: National Defence Academy and Austrian Ministry of Defence and Sports.

Kempadoo, K. (2005). (Ed.), Trafficking and Prostitution Reconsidered. Boulder: Paradigm Publishers. 
Lobasz, J. k. (2010). Beyond Border Security: Feminist Approaches to Human Trafficking. In L. Sjoberg, (Ed.), Gender and International Security: Feminist Perspectives (pp. 214-234). New York: Routledge.

Nair, P. M. and Sankar, S. (2005). Trafficking in Women and Children in India. New Delhi: Orient Longman.

Plate, E. J. (2006). Disaster Prevention. In E. Ehlers and T. Krafft, (Eds.), Earth System Science in the Anthropocene: Emerging Issues and Problems (pp. 87-112). New York: Springer, 2006.

SAARC Convention on Preventing and Combating Trafficking of Women and Children for Prostitution. 2002. Retrieved on February 9, 2010 from http:/www.saarc-sec.org/userf iles/conv-traffiking.pdf

Samarasinghe, V. (2008). Female Sex Trafficking in Asia: The Resilience of Patriarchy in a Changing World. New York: Routledge.

Selling and buying of kidney. (September 3, 2011). The Daily Jaijai Din.

Shamim, I. (2010). State of Trafficking in Women and Children and their Sexual Exploitation in Bangladesh. Dhaka: Centre for Women and Children Studies (CWCS).

Shelley, L. (2010). Human Trafficking: A Global Perspective. New York: Cambridge University Press.

Singh, K. and Kapur, D. (2011). Law, Violence, and the Girl Child. Health and Human Rights, 5 (2), 8-29.

Stockholm International Peace Research Institute (SIPRI). 2010. Retrieved on November 20, 2011 from http:/www.sipri.org/ yearbook/2011/04/04A

Tadjbakhsh, S. and Chenoy, A. M. (2007). Human Security: Concepts and Implications. New York: Routledge.

The Dawn. March 1, 2011 "India raises defence budget to \$36.5 billion." Retrieved on November 10, 2011 from http://dawn.com/2011/03/01/india-raises-defence-budget-to-365-bi llion/

The New York Times, "Indian Activist Attempts Revival of Antigraft Drive." Retrieved on September 1, 2013 from http://www.nytimes.com/2012/03/26/world/asia/anna-hazare-triesto-renew-anti-corruption-movement.html

The US Department of State (2006-2012). Trafficking in Persons Report. Washington, DC: The US Department of State.

Thomas, C. (2000). Global Governance and Human Security. London: Pluto Press.

Transparency International, "What is the Corruption Perception Index? Retrieved on February 20, 2013 from

http://www.transparency.org/cpi2011/in_detail\#myAnchor1

Transparency International, "Breaking the Chain: Trafficking and Corruption," Retrieved on February 20, 2013 from http://archive.transparency.org/news_room/in_focus/2011/breakin $\mathrm{g}$ the chain corruption and human trafficking

UNDP (1994). Human Development Report. New York: Oxford University Press.

UNDP Human Development Report (2011)."Table 4: Gender Inequality Index and related indicators." Retrieved on September 3 , 2011 from http://hdr.undp.org/en/media/HDR_2011_EN_Table4.p df

UNODC (2004). United Nations Convention against Transnational Organized Crimes and the Protocols Thereto. New York: United Nations.

Weaver, O. (1995). Securitization and Desecuritization. In R. D. Lipschutz, (Ed.), On Security (pp. 46-86). New York: Columbia University Press.

World Bank (1997). Helping Countries Combat Corruption: The Role of the World Bank. Washington, DC: World Bank. 